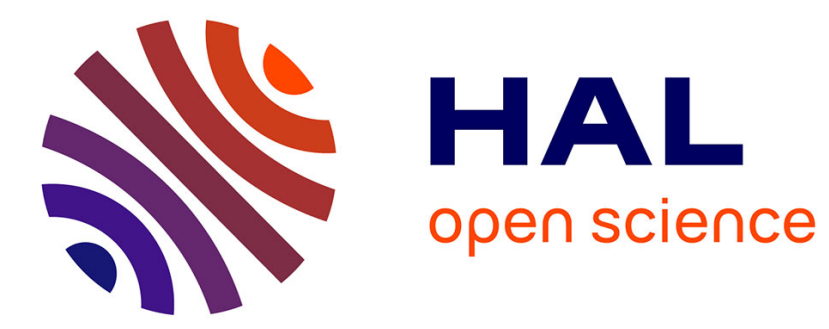

\title{
Effects of damping on brake squeal coalescence patterns - application on a finite element model
}

\author{
Guillaume Fritz, Jean-Jacques Sinou, Jean-Marc Duffal, Louis Jezequel
}

\section{To cite this version:}

Guillaume Fritz, Jean-Jacques Sinou, Jean-Marc Duffal, Louis Jezequel. Effects of damping on brake squeal coalescence patterns - application on a finite element model. Mechanics Research Communications, 2007, 34 (2), pp.181-190. 10.1016/j.mechrescom.2006.09.012 . hal-00207796

\section{HAL Id: hal-00207796 \\ https://hal.science/hal-00207796}

Submitted on 18 Jan 2008

HAL is a multi-disciplinary open access archive for the deposit and dissemination of scientific research documents, whether they are published or not. The documents may come from teaching and research institutions in France or abroad, or from public or private research centers.
L'archive ouverte pluridisciplinaire HAL, est destinée au dépôt et à la diffusion de documents scientifiques de niveau recherche, publiés ou non, émanant des établissements d'enseignement et de recherche français ou étrangers, des laboratoires publics ou privés. 
Journal home page: http://www.sciencedirect.com/science/journal/00936413

Effects of damping on brake squeal coalescence patterns application on a finite element model

Mechanics Research Communications, Volume 34, Issue 2, March 2007, Pages 181-190

Guillaume Fritz, Jean-Jacques Sinou, Jean-Marc Duffal and Louis Jezequel

\title{
Effects of Damping on Brake Squeal Coalescence Patterns - Application on a Finite Element Model
}

Guillaume FRITZ1 ${ }^{2}$, Jean-Jacques SINOU*2, Jean-Marc DUFFAL ${ }^{1}$, Louis JÉZÉQUEL ${ }^{2}$

1 Renault SAS, Direction de la Recherche, Groupe Acoustique, 1 avenue du Golf 78288 Guyancourt cedex

2 Laboratoire de Tribologie et Dynamique des Systèmes UMR-CNRS 5513, Ecole Centrale de Lyon, 36 avenue Guy de Collongue, 69134 Ecully Cedex, France

\begin{abstract}
Brake squeal is referred to, in most publications, as a flutter instability trigged by a mode coupling phenomenon. A lot of clues tends to prove that damping would be a key parameter in brake squeal modelling. This study aims at investigating the effects of damping on coalescence patterns, that is to say on the way the modes couple. A finite element model of the whole brake corner has been used to compute the brake modal behaviour. Then a complex eigenvalue analysis has been undertaken to assess the brake stability as a function of the friction coefficient. Different kinds of damping spreading over the modes have been studied. Two main effects have been noticed: a shifting effect and a smoothing effect. The first one always stabilize the brake, whereas this is not the case of the second one. The combination of the two effects may make the brake more unstable depending on the spreading of the additionnal damping.
\end{abstract}

\section{Introduction}

Brake squeal analysis is a field of mechanical engineering that has improved for the past ten years. Most of the works published on this subject are based on a technique called Complex Eigenvalue Analysis $(C E A)$. The real and imaginary parts of the complex eigenvalues are respectively responsible for the stability and for the frequency of the corresponding modes. This technique has been used on lumped models first(see for example [1], [2], [3], [4], [5], [6]). Then, thanks to an increase in computer capabilities, it has been extended to finite element $(F E)$ models. This method, which highlights the phenomenon referred to as mode coupling or coalescence, is now well known. Nevertheless, a lot of work remains to be done on the effects of damping. Indeed, a brake system features several kinds of damping, such as structural 


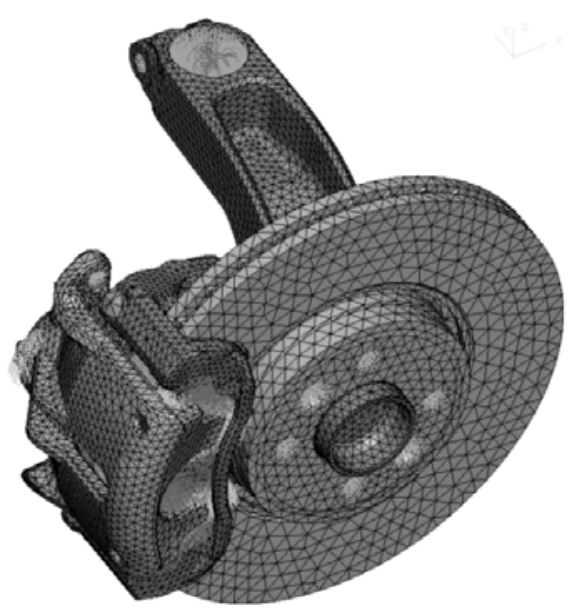

Figure 1: Finite Element Model

damping, friction induced damping. Moreover, damping addition by means of insulators often succeed in fixing squeal problems. Therefore the effects of damping must be taken into account in an accurate squeal model.

On the one hand, the effects of damping have already been investigated on lumped models [7], [8], [9], [10]. On the other hand, taking damping into account in a whole brake FE model is far more complicated. Thus most of the published works based on FE models neglect damping. To account for this hypothesis, the following rule of thumb is invoked: the undamped situation must be the worst one. Nevertheless, some researchers have taken an overall damping value into account [11], [12], [13]. In most cases, a constant loss factor is applied on the whole frequency range. Some other researchers have focused on an accurate modelling of damping sources: friction induced damping [14], [15], [16] and shims [17], [18], [19].

Most of the studies based on FE models have been undertaken for one or a few given values of the friction coefficient. As a consequence, it is difficult to track the modes with respect to the friction coefficient in order to understand the mode coupling phenomenon. This paper focuses on this aspect of brake squeal. Indeed, curves that show the transition between a stable and an unstable behaviour of the brake have been accurately displayed and referred to as coalescence patterns. Then, the effects of modal damping on those coalescence patterns have been investigated.

\section{Methodology}

\subsection{Modal equation computed from FE model}

This study begins with the building of a FE model corresponding to a commercial brake. The scope of this model includes disc, pads, caliper, anchor bracket, hub and knuckle. It features 528000 degrees of freedom and is displayed in figure 1. Its equation of motion may be written as:

$$
\mathbf{M u ̈}+\mathbf{C} \dot{\mathbf{u}}+\mathbf{K u}=0
$$


Where $\mathbf{M}, \mathbf{C}, \mathbf{K}$ are respectively the mass, damping and stiffness matrices. $\mathbf{u}$ is the displacement vector and dot denotes derivative with respect to time. Because of friction, the stiffness matrix has specific properties:

$$
\mathbf{K}=\mathbf{K}_{\text {Structure }}+\mu \mathbf{K}_{\text {Friction }}
$$

Where $\mathbf{K}_{\text {Structure }}$ is the structural stiffness matrix, $\mathbf{K}_{\text {Friction }}$ the asymmetrical friction induced stiffness matrix and $\mu$ the friction coefficient. For the sake of brevity, the procedure to compute $\mathbf{K}_{\text {Friction }}$ will not be presented here (cf [20], [21], [22] and [23]).

The undamped non-friction case is noteworthy, because FEM softwares can easily solve equation 1 in that case by computing the normal modes of the brake. Let $\boldsymbol{\Psi}$ be the undamped non-friction modal basis of the brake. Assuming that $\boldsymbol{\Psi}$ has been normalized with respect to the mass matrix, the projection of equation 1 on this particular modal basis gives in the frequency domain:

$$
\left[\mathbf{I} s^{2}+\mathbf{D} s+\left(\boldsymbol{\Omega}^{2}+\mu \boldsymbol{\Lambda}_{\mathbf{f}}\right)\right] \boldsymbol{\Gamma}=0
$$

where $\mathbf{I}$ is the identity matrix. $\mathbf{D}$ and $\boldsymbol{\Lambda}_{\mathbf{f}}$ are respectively projections of $\mathbf{C}$ and $\mathbf{K}_{\text {Friction }}$ on the modal basis $\boldsymbol{\Psi} . \boldsymbol{\Omega}^{\mathbf{2}}$ is given by

$$
\mathbf{\Omega}^{\mathbf{2}}=\operatorname{diag}\left(\omega_{1}^{2} \cdots \omega_{n}^{2}\right)
$$

with $\omega_{1}, \cdots, \omega_{n}$ the undamped non-friction frequencies of the system. $s$ denotes the Laplace parameter and $\boldsymbol{\Gamma}$ the eigenvector coordinates in the modal basis $\boldsymbol{\Psi}$.

In order to be solved, equation 3 can be rewritten as a general eigenvalue problem by doubling the space of states. It must be kept in mind that for a given brake, only $\mathbf{D}$ and $\mu$ are unknown in equation 3. In the following parts, the brake behaviour will be assessed with respect to both of these parameters.

\section{Effect of damping on coalescence patterns}

\subsection{Undamped coalescence}

Equation 1 becomes, in the undamped case, an eigenvalue problem depending on the friction coefficient value. Therefore the results, that is to say the eigenvalues, have been plotted in black in figures 2 and 3 as functions of this parameter. The first point to notice is that the eigenvalues are complex valuated. The real and imaginary parts of an eigenvalue account respectively for the stability and the frequency of the corresponding mode. A positive real part means an unstable mode.

For the sake of comprehension, the results have be presented on a narrow frequency range. This range contains only two modes which will be named Mode $A$ and Mode $B$ by increasing frequencies. The black curves of Figure 2 and 2 displays the frequencies and real parts of the two modes as a function of the friction coefficient. The curves highlights the phenomenon referred to as mode coupling or coalescence between Mode $A$ and Mode $B$. These phrases are easy to understand since it deals with two modes apart in the frequency range for $\mu=0$, which tends to get closer as the friction increases. The two modes reach the same frequency at a point known as coalescence point. Beyond this point, the frequencies of the two modes remain equal, but their real parts become non zero and opposite. Therefore one is stable (displayed as a point) whereas the other one is unstable (displayed as a cross). Note that the displayed data have been normalized with respect to the coordinates of the coalescence point. 


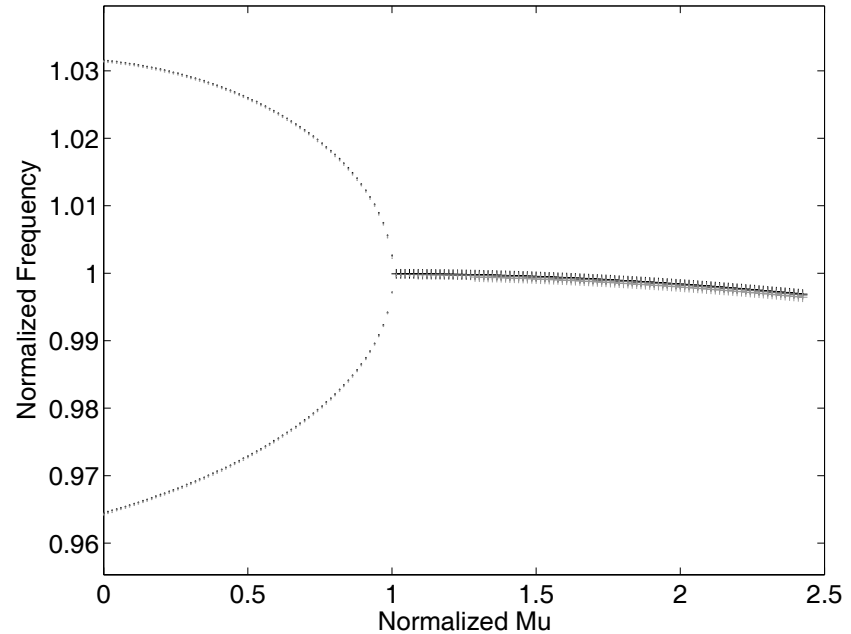

Figure 2: Equally damped - Frequency $=f(\mu)$

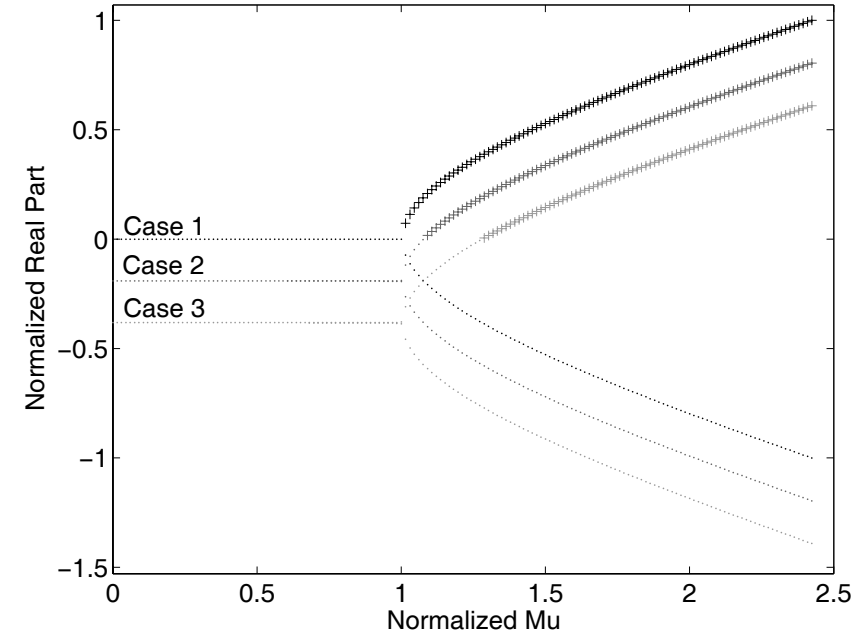

Figure 3: Equally damped - Real part $=f(\mu)$

In a practical point of view, it is very useful to compute the friction coefficient value, called $\mu_{c}$, that marks the border between a stable and an unstable behaviour. By increasing the friction coefficient from zero, $\mu_{c}$ is defined as the last value that does not induce an eigenvalue with a positive real part. Table 1 gathers the $\mu_{c}$ values corresponding to this section and to the following ones. $d_{A}$ and $d_{B}$ denote respectively the damping of Mode $A$ and Mode $B$. The presented modes are two out of the first 75 modes of the brake, which have been computed. The analysis of the eigenvalues variability as a function of the friction coefficient expects the brake to feature six unstable modes on the overall studied frequency range.

\subsection{Equally damped coalescence}

In this section, the example of Mode $A$ and Mode $B$ is reconducted. These two modes are equally damped. It means that

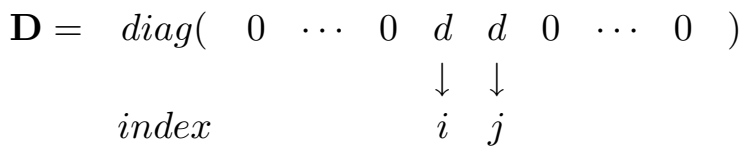

Where $i$ and $j$ are respectively the indices of Mode $A$ and Mode $B$ in the modal matrices.

Figures 2 and 3 gather the results corresponding to three values of $d$. As mentioned before, the black curves are for the undamped situation $(d=0)$. As previously explained by Hoffmann and Gaul [10], and Sinou and Jézéquel [5], increasing the value of $d$ decreases the real part by "'lowering the real part curves"', whereas the frequencies remain constant. As a consequence, the eigenvalues cross the real part $=0$ axis for a higher value of the friction coefficient. Therefore the more damped the brake is, the more stable it becomes. This conclusion is confirmed in table 1 as an increase in $\mu_{c}$. 

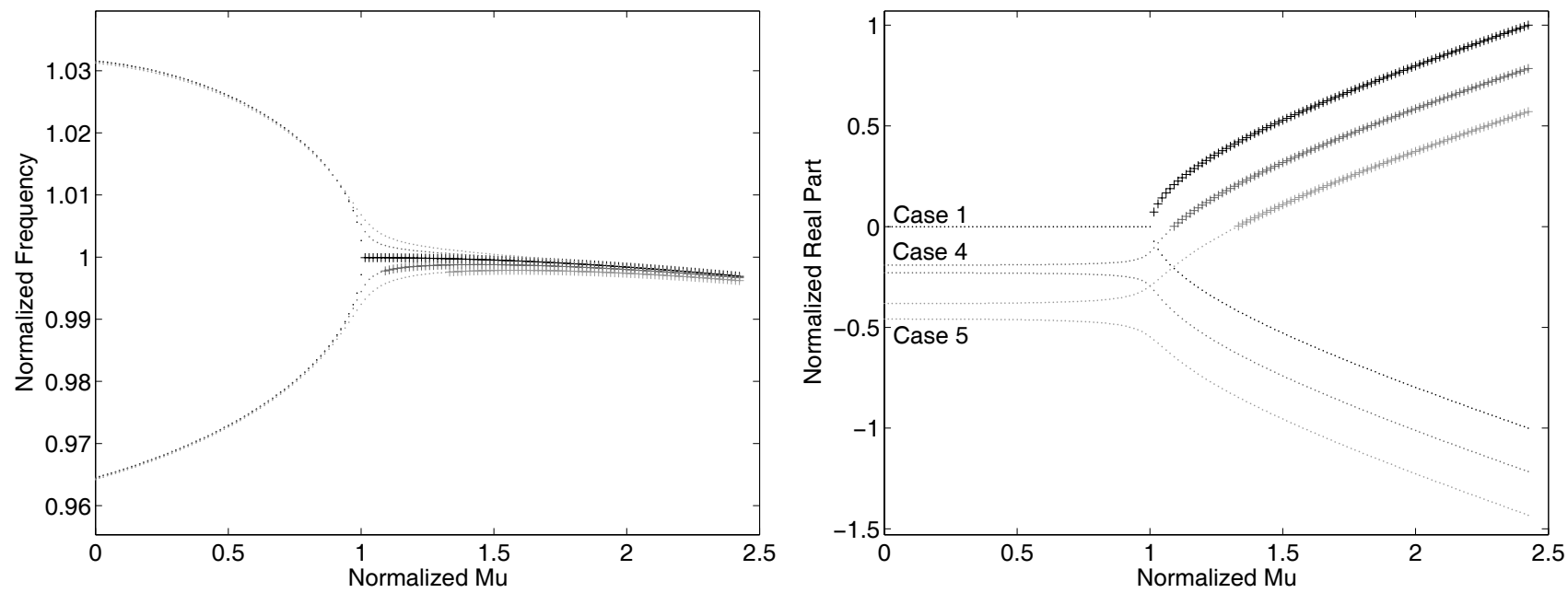

Figure 4: Non-equally damped - Frequency $=f(\mu)$ Figure 5: Non-equally damped - Real part $=f(\mu)$

\subsection{Non-equally damped coalescence}

\subsubsection{Little difference in damping}

Mode $A$ and Mode $B$ are now supposed to be non-equally damped. Mode $B$ has been chosen to be $20 \%$ more damped than Mode $A$. In this case, the damping matrix is:

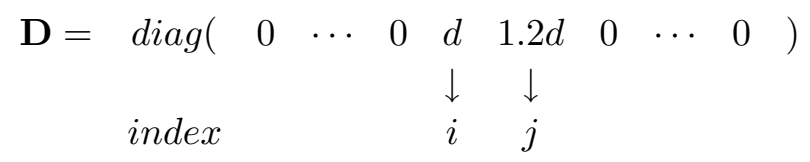

This kind of damping matrix deeply alters coalescence patterns, as displayed in figures 4 and 5 . As expected, increasing $d$ tends mainly to shift the curves towards the real part negative values. Thus the brake behaviour is improved in terms of stability, as illustrated in table 1 by an increase in $\mu_{c}$. Nevertheless, the coupling patterns are far more complicated than previously. First of all, this damping distribution induces a gap in real part between the two modes at $\mu=0$. Then, the main change happens in the vicinity of the coalescence point. The transition is less sharp than previously. As explained by Hoffmann and Gaul [10], a "smoothing effect"' of the curves with respect to the friction coefficient is observed, both for real parts and frequencies. As a consequence, the real parts seem to begin splitting at a lower friction coefficient value than for the undamped situation. Moreover the higher the damping difference is, the larger the gap in frequency is between the two modes. Even if coalescence patterns are more complicated than previously, they feature a noteworthy advantage. Indeed, thanks to the frequency and real part shifts, that are non-zero for each friction values, the unstable mode can now be clearly identified and tracked with respect to the friction coefficient value. Here, the unstable mode turns out to be the less damped one. 

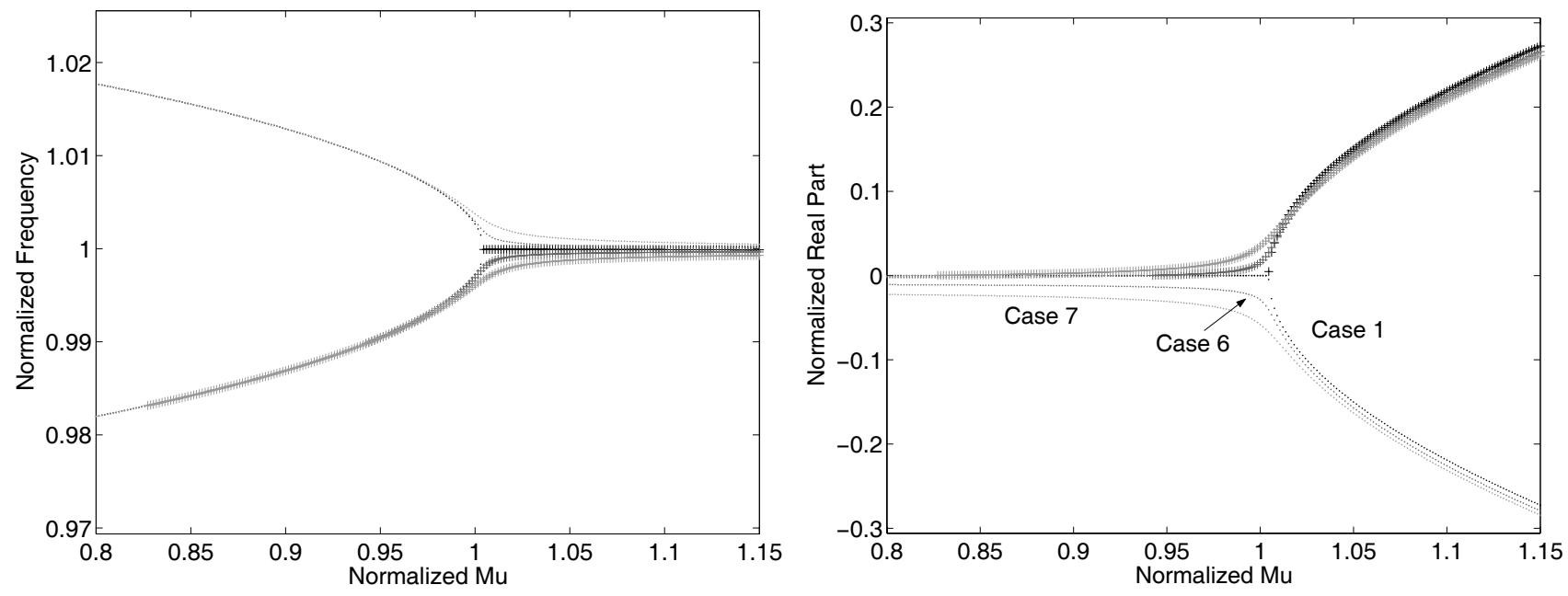

Figure 6: Non-equally damped - Frequency $=f(\mu)$ Figure 7: Non-equally damped - Real part $=f(\mu)$

\subsubsection{Large difference in damping}

So far, an increase in damping seems to stabilize the system. It shifts the curves towards the negative real part values and therefore induces an increase in $\mu_{c}$. Nevertheless, that is not always true. Indeed a difference in damping has two main effects on coalescence curves : a "lowering effect"' for the real part values, and a "smoothing effect"' in the vicinity of the coalescence point. The first effect was overwhelming in the previous section curves. But with a large difference in damping between the two modes, the second effect may prevail, as illustrated in figures 6 and 7 . The two damped curves plotted on these figures feature respectively a ratio of 2.5 to 1 and 5 to 1 between the dampings of the two modes. In these cases, the smoothing effect induces a significant drop in $\mu_{c}$ as written in table 1 . In order to illustrate that point, figure 8 displays in detail the crossing of the real part $=0$ axis.

\section{$4 \quad$ Stability areas}

This section aims at synthetizing the effect of damping on the brake stability. It can be inferred from the last section, that the ratio between the dampings of the two modes highly influence the brake stability. Thus, a specific study has been undertaken to investigate the stability areas of the brake.

In a first analysis, the damping of Mode $A$ has been set to a non-zero constant value. The damping of Mode $B$ has been chosen so that the ratio $d_{B} / d_{A}$ ranges from 0 to 20 . Figures 9 and 10 display the stability charts $\left(\mu, d_{B} / d_{A}\right)$ respectively with $d_{A}=1$ and $d_{A}=10$. For each couple of values, the brake stability has been assessed through the sign of the eigenvalue real parts. The gray area is unstable whereas the white area is stable. Note that the ordinate scale is not linear. The abscissa of the border between the two areas is by definition $\mu_{c}$. When the two dampings are very different each other $\left(d_{B} / d_{A}<<1\right.$ or $d_{B} / d_{A}>>1$ ), the stability is drastically worsen. Here, for $d_{A}=1$ and $d_{A}=10$, the optimal case in terms of stability turns out to be the equally damped case $\left(d_{B} / d_{A}=1\right)$. Nevertheless, slight differences can be noticed between the two charts, especially for high values of the $d_{B} / d_{A}$ ratio. 


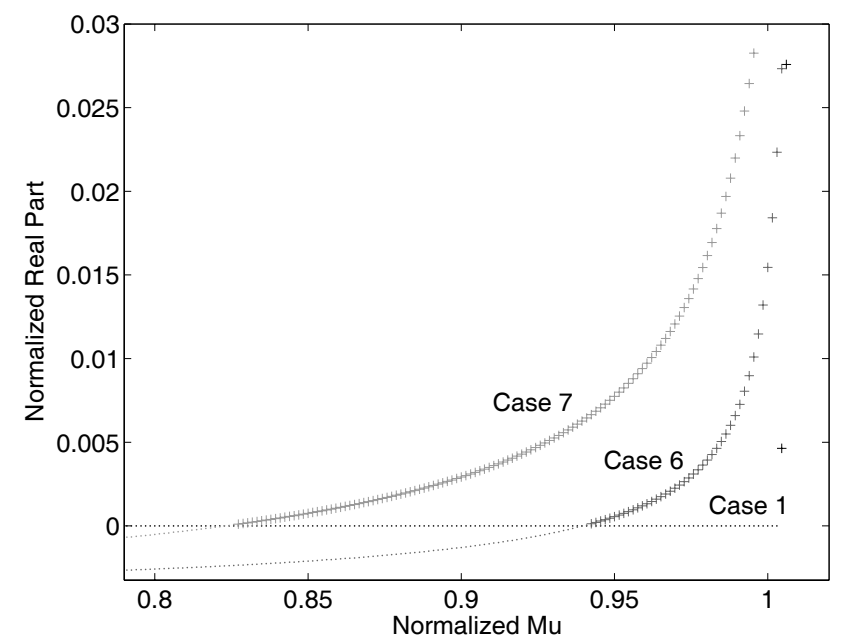

Figure 8: Non-equally damped coalescence patterns - Zoom

\begin{tabular}{|l||c|c|c|c|c|}
\hline Situation & Case & $d_{A}$ & $d_{B}$ & $d_{B} / d_{A}$ & $\mu_{c}$ \\
\hline \hline Undamped & 1 & 0 & 0 & - & 1.00 \\
\hline \multirow{2}{*}{ Equally damped } & 2 & 50 & 50 & 1.0 & 1.07 \\
\cline { 2 - 6 } & 3 & 100 & 100 & 1.0 & 1.27 \\
\hline \multirow{2}{*}{ Little damping difference } & 4 & 50 & 60 & 1.2 & 1.07 \\
\cline { 2 - 6 } & 5 & 100 & 120 & 1.2 & 1.32 \\
\hline Large damping difference & 6 & 1 & 2.5 & 2.5 & 0.94 \\
\cline { 2 - 6 } & 7 & 1 & 5 & 5.0 & 0.82 \\
\hline
\end{tabular}

Table 1: Critical values of the friction coefficient

In order to make sure the previous conclusion is true for all values of $d_{A}$, a fullfactorial design of experiment has been launched as functions of $d_{A}$ and $d_{B}$. Figures 11 and 12 show the results as stability areas in the $\left(d_{A}, d_{B}\right)$ plane, just below the undamped $\mu_{c}$. Figures 11 and 12 are respectively for $\mu=\left(\mu_{c}\right)_{\text {undamped }}-2 \epsilon$ and $\mu=\left(\mu_{c}\right)_{\text {undamped }}-\epsilon$, with $0<\epsilon<<1$. On these charts, the stability borders are smooth and the areas are triangle shaped. The higher $\mu$, the sharper the stable triangle is. For $\mu>\left(\mu_{c}\right)_{\text {undamped }}$, the vertex of the triangle (ie $d_{A}=d_{B}=0$ ) becomes unstable, and then the stable area is shifted toward the right upper corner of the chart.

\section{Conclusion}

In this paper, the effects of damping on the brake squeal mode coupling phenomenon have been investigated with a FE based method. The modal behavior of the brake has been extracted first from FE computation. Then, friction has been implemented so as to display accurately the brake eigenvalues as a 


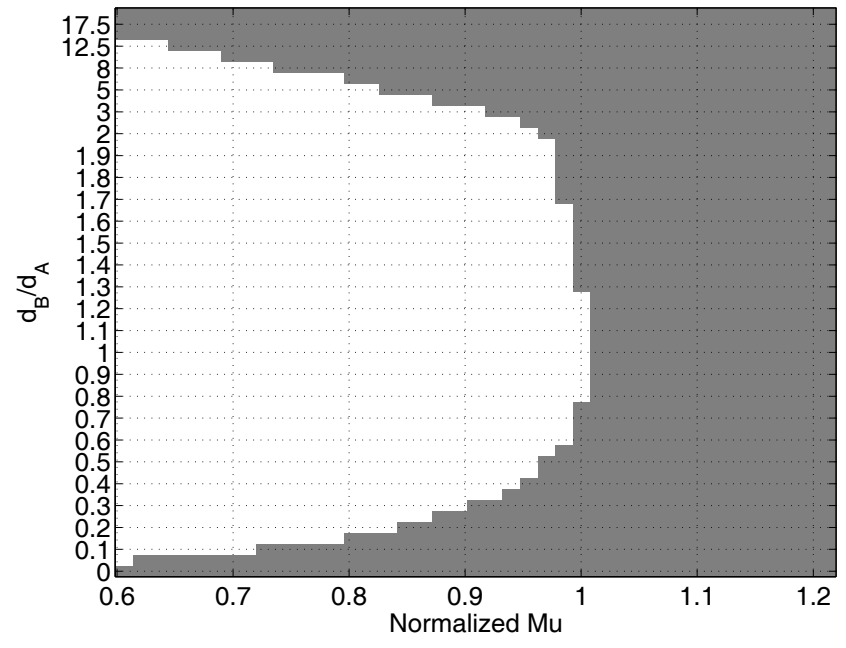

Figure 9: $\left(\mu, d_{B} / d_{A}\right) ; d_{A}=1$

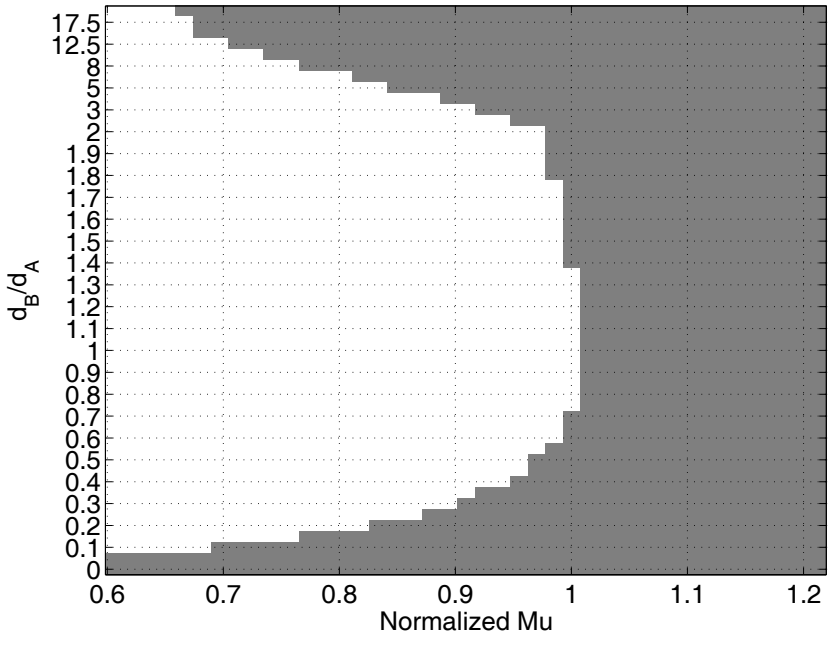

Figure 10: $\left(\mu, d_{B} / d_{A}\right) ; d_{A}=10$

function of the friction coefficient. These curves depict the coalescence patterns which are characteristic of the mode coupling phenomenon. The effects of modal damping on these patterns has been assessed for several kinds of spreading over the modes. The results turns out to be more complicated than the common idea "damping always stabilize the system". If damping is equally distributed on the two modes involved in the mode coupling phenomenon, the only effect is a shift of the curves toward the negative real parts. If damping is spread non-equally over the two modes, a shifting and a smoothing effect can be seen on coalescence curves. If the ratio in damping between the two modes is sufficient, an increase in damping tends to make the brake unstable for a lower value of the friction coefficient. So in this case, the common idea is wrong. In order to detail this point, two kinds of stability areas have been plotted involving the damping of the two modes and the friction coefficient.

\section{References}

[1] Ibrahim R.A., 1994. "Friction-Induced Vibration, Chatter, Squeal, and Chaos. Part 2 : Dynamics and Modeling". ASME Design Engineering Technical Conferences, 7, pp. 209-2269.

[2] Earles S.W.E., and Lee C.K., 1976. "Instabilities Arising from the Frictional Interaction of a Pin-Disc System Resulting in Noise Generation". Trans. ASME J. Engng Ind., 1, pp. 81-86.

[3] Kinkaid N.M., O’Reilly O.M., and Papadopoulos P., 2003. "Automotive disc brake squeal". Journal of Sound and Vibration, 267, pp. 105-166.

[4] Ouyang H., Mottershead, Cartmell J.E.M.P., and Brookfield D.J., 1999. "Friction-induced vibration of an elastic slider on a vibrating disc". Journal of Mechanical Sciences, 41(3), pp. 325336. 


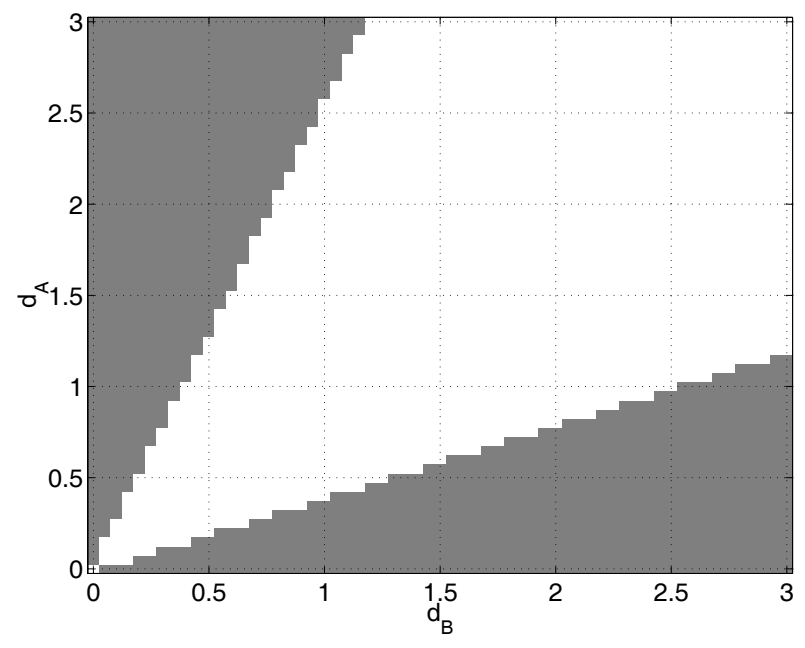

Figure 11: $\left(d_{A}, d_{B}\right) ; \mu=\left(\mu_{c}\right)_{\text {undamped }}-2 \epsilon$

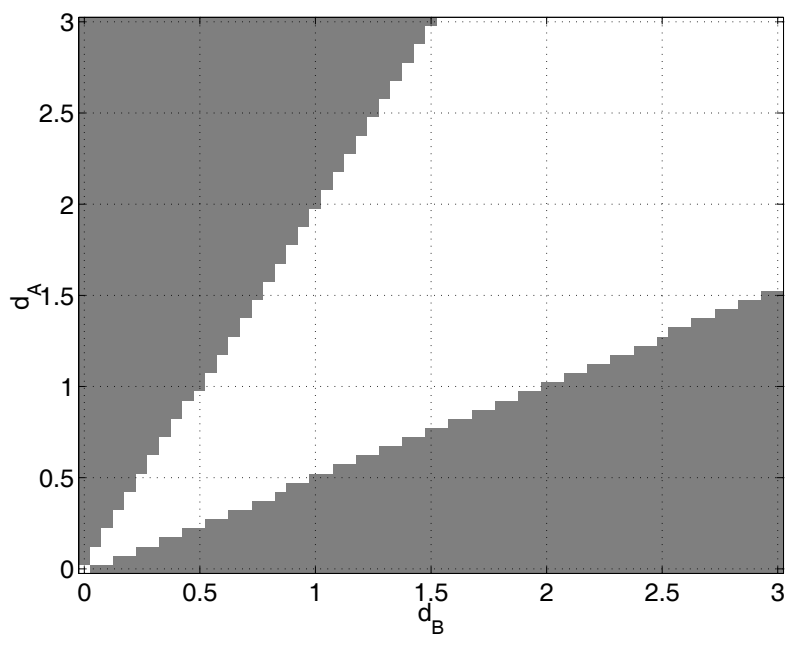

Figure 12: $\left(d_{A}, d_{B}\right) ; \mu=\left(\mu_{c}\right)_{\text {undamped }}-\epsilon$

[5] Sinou J-J., and JÉzÉQuel L., 2006. "Mode coupling instability in friction induced vibrations and its dependency on system parameters including damping". Journal of European Mechanics - A/Solids, In press, pp. $1-16$.

[6] Sinou J-J., Thouverez F., and JÉzÉquel L., 2003. "Analysis of friction and instability by the center manifold theory for a non-linear sprag-slip model". Journal of Sound and Vibration, 265(3), pp. $527-559$.

[7] Earles S.W.E., and Chambers P.W., 1987. "Disc brake squeal noise generation: predicting its dependency on system parameters including damping". Int. J. of Vehicle Design, vol. 8, nos 4/5/6, pp. $538-552$.

[8] Shin K., Oh J-E., and Brennan M.J., 2002. "Nonlinear analysis of friction induced vibrations of a two degree of freedom model for disc brake squeal noise". JSME International Journal, 45, pp. $426-432$.

[9] Shin K., Brennan M.J., Oh J-E., and Harris C.J., 2002. "Analysis of disc brake noise using a two-degree-of-freedom model.". Journal of Sound and Vibration, 254, pp. 837-848.

[10] Hoffmann N., and Gaul L., 2003. "Effects of damping on mode-coupling instability in friction induced oscillations". ZAMM Z. Angew. Math. Mech., 83, N8, p. 524534.

[11] LiLES G.D., 1989. "Analysis of disc brake squeal using finite element methods". SAE technical paper 891150, Traverse City, Michigan, USA.

[12] Kung S.W., Saligrama V.C., and Riehle M.A., 2000. "Modal participation analysis for identifying brake squeal mechanism". SAE technical paper 2000-01-2764, San Diego, California, USA. 
[13] Shi T.S., Dessouki O., Warzecha T., Chang W.K., and Jayaundera A., 2001. "Advances in complex eigenvalue analysis for brake noise". SAE technical paper 2001-01-1603, Traverse City, Michigan, USA.

[14] Bajer A., Belsky V., and Kung S.W., 2004. "The influence of friction-induced damping and nonlinear effects on brake squeal analysis". SAE technical paper 2004-01-2794, Anaheim, California, $U S A$.

[15] Kung S.W., Stelzer G., Belsky V., and BAJer A., 2003. "Brake squeal analysis incorporating contact conditions and other nonlinear effetcs". SAE technical paper 2003-01-3343, Hollywood, Florida, USA.

[16] BAJer A., Belsky V., and Zeng L.J., 2003. "Combining a nonlinear static and complex eigenvalue extraction in brake squeal simulation". SAE technical paper 2003-01-3349, Hollywood, Florida, USA.

[17] FLinT J., 2003. "A review of theories on constrained layer damping and some verification measurements on shim material". SAE technical paper 2003-01-3321, Hollywood, Florida, USA.

[18] Mignery L., Wang J., and Luo J., 2001. "Prediction of damper effects in a brake system model". SAE technical paper 2001-01-3140, New Orleans, Louisiana, USA.

[19] McDaniel J.G., Li X., Elvenkemper A., Wegmann E., Wang W.A., Chen S.E., and Flint J., 2005. "Simulating the effect of insulators in reducing disc brake squeal". SAE technical paper 2005-01-3944, Orlando, Florida, USA.

[20] Chung C.H.J, Steed W., Dong J.D., Kim B.S., and Ryu G.S., 2003. "Virtual design of brake squeal". SAE technical paper 2003-01-1625, Traverse City, Michigan, USA.

[21] Chung C.H.J, Steed W., Kobayashi K., and Nakata H., 2001. "A new analysis method for brake squeal part i : Theory for modal domain formulation and stability analysis". SAE technical paper 2001-01-1600, Traverse City, Michigan, USA.

[22] Nakata H., Kobayashi K., Kajita M., and Chung C.H.J, 2001. "A new analysis approach for motorcycle brake squeal noise and its adaptation". SAE technical paper 2001-01-1850, Pisa, Italy.

[23] Huang J., Krousgrill C.M., and Bajaj A.K., 2006. "Modeling of automotive drum brakes for squeal and parameter sensitivity analysis". Journal of Sound and Vibration, 289, pp. 245-263. 